M. Lichtwarck-Aschoff

A. M. Markström

A. J. Hedlund

J. B. Nielsen

K. A. Nordgren

U. H. Sjöstrand

\title{
Oxygenation remains unaffected by increased inspiration-to-expiration ratio but impairs hemodynamics in surfactant-depleted piglets
}

Abstract Objectives: Prolongation of inspiratory time is used to reduce lung injury in mechanical ventilation. The aim of this study was to isolate the effects of inspiratory time on airway pressure, gas exchange, and hemodynamics, while ventilatory frequency, tidal volume, and mean airway pressure were kept constant.

Design: Randomized experimental trial.

Setting: Experimental laboratory of a University Department of Anesthesiology and Intensive Care. Animals: Twelve anesthetised piglets. Interventions: After lavage the reference setting was pressure-controlled ventilation with a decelerating flow; I: E was 1:1, and PEEP was set to $75 \%$ of the inflection point pressure level. The $\mathrm{I}: \mathrm{E}$ ratios of $1.5: 1,2.3: 1$, and $4: 1$ were applied randomly. Under open lung conditions, mean airway pressure was kept constant by reduction of external PEEP.

Measurements and results: Gas exchange, airway pressures, hemodynamics, functional residual capacity ( $\mathrm{SF}_{6}$ tracer), and intrathoracic fluid volumes (double indicator dilution) were measured. Compared to the I:E of $1: 1$, $\mathrm{PaCO}_{2}$ was $8 \%$ lower, with $\mathrm{I}: \mathrm{E}$ 2.3:1 and 4:1 $(p \leq 0.01)$ while $\mathrm{PaO}_{2}$ remained unchanged. The decrease in inspiratory airway pressure with increased inspiratory time was due to the response of the pressureregulated volume-controlled mode to an increased I:E ratio. Stroke index and right ventricular ejection fraction were depressed at higher $\mathrm{I}: \mathrm{E}$ ratios (SI by $18 \%$ at $2.3: 1,20 \%$ at $4: 1$; RVEF by $10 \%$ at $2.3: 1,13 \%$ at $4: 1 ; p \leq 0.05$ ).

Conclusion: Under open lung conditions with an increased I:E ratio, oxygenation remained unaffected while hemodynamics were impaired.

Key words Pressure-controlled inverse ratio ventilation . Endinspiratory pressure $\cdot$ Intrinsic PEEP - Functional residual capacity $\cdot$ Hemodynamics

\section{Introduction}

A growing body of evidence exists that high airway pressures should be avoided during mechanical ventilation to avoid further aggravation of the underlying lung injury [1-3]. To achieve this goal, prolongation of the inspiratory time to the point of inverting the inspiration-to-expiration (I:E) ratio seems promising [4-9]. Controlled trials in patients have been published 
[9-12], and, as pointed out by Marini and Kelsen [13], additional prospective controlled trials in patients are needed. To investigate the effects of prolonged inspiratory time we chose an animal experimental model. The aim of this study was to isolate the effects of inspiratory time on airway pressure, gas exchange, and hemodynamics, while keeping mean airway pressure constant. Under open lung conditions, no improvement in oxygen tension was expected when mean airway pressure was kept constant, but prolongation of the inspiratory time was anticipated ultimately to impair hemodynamics.

\section{Material and methods}

Preparation of the animals

Two papers describing in detail the methods used have been previously published $[14,15]$. Twelve healthy piglets of a Swedish country breed $(25.4 \pm 1.9 \mathrm{~kg})$ were examined. Premedication consisted of $15 \mathrm{mg} / \mathrm{kg}$ pentobarbital and $0.5 \mathrm{mg}$ atropine administered intraperitoneally $15 \mathrm{~min}$ prior to induction. Induction was achieved with $500 \mathrm{mg}$ ketamine and $0.5 \mathrm{mg}$ atropine i.v. followed by $20 \mathrm{mg}$ morphine and ketamine i.v. at $20 \mathrm{mg} \mathrm{kg}^{-1} \mathrm{~h}^{-1}$. Pancuronium bromide $\left(0.26 \mathrm{~m} \mathrm{~kg}^{-1} \mathrm{~h}^{-1}\right)$ was used as relaxant. The animals were tracheostomized and ventilated through an $8-\mathrm{mm}$ endotracheal tube (Mallinckrodt, Glens Falls, N.Y., USA) with a Servo 300 ventilator (Siemens-Elema, Solna, Sweden). A thermostatically controlled heating pad was used to keep the animal's temperature at $37.6^{\circ} \pm 0.6^{\circ} \mathrm{C}$.

The investigations were performed at the experimental laboratory of the Department of Anesthesiology and Intensive Care at the University Hospital in Uppsala. The local ethics committee for animal experimentation reviewed and approved the protocol.

\section{Monitoring}

Intravascular catheters were surgically placed for the measurement of central venous, pulmonary artery pressure (via the external jugular vein), and aortic pressure (via the carotid artery). The exact position of catheters was confirmed by pressure tracing. All pressures were displayed on a bedside monitor (Siemens Sirecust) and recorded with reference to the middle thorax, and end-expiration. Heart rate, arterial and venous blood gases were all recorded $(\mathrm{ABL}$ 300, Radiometer A/S, Copenhagen, Denmark). Carbon dioxide production was recorded by a metabolic monitor (Datex Deltatrac, Datex Instrumentation, Helsinki, Finland).

The estimation of cardiac output was performed using the COLD system (Pulsion Medizintechnik, Munich, Germany). A fiberoptic catheter was introduced via the femoral artery and advanced to the descending aorta. The thermistor in the femoral artery catheter connected to the COLD system detects the temperature signal in the descending aorta from which cardiac output is calculated [16]. Right ventricular end-diastolic volume was measured according to the technique described previously [17]. Extravascular lung water (EVLW) and intrathoracic blood volume were measured using double indicator dilution as described in detail elsewhere $[16,18]$. The double indicator consisted of $10 \mathrm{mg}$ indocyanine green mixed in $10 \mathrm{ml} 5 \%$ dextrose in water at a temperature of $5^{\circ}-7^{\circ} \mathrm{C}$ and was injected as a bolus into the superior vena cava. The dilution curves for dye and temperature were recorded simultaneously in the descending aorta with the thermistor-tipped fiberoptic catheter. EVLW was calculated as the difference between the volume accessible to the thermal indicator and the volume accessible to the intravascular indicator, indocyanine green. Intrathoracic blood volume was calculated as the product of cardiac output and the mean transit time of indocyanine green between the injection and detection points.

Airway pressures were obtained from the Servo 300 digital displays. Before starting the study the pressure and flow transducers of the Servo 300 were calibrated with independent devices. Every morning a functional check was performed according to the procedure given in the operating manual of the Servo 300 .

Static chest-lung compliance was calculated according to the formula: tidal volume/(end-inspiratory pressure - end-expiratory pressure). When end-inspiratory pressure and total PEEP were measured, the hold functions of the Servo 300 were used for $5 \mathrm{~s}$ before the equilibrium values were noted. In this study total PEEP was defined as the sum of external PEEP (set by the PEEP valve of the ventilator) and intrinsic PEEP. Total PEEP was measured by the end-expiratory hold procedure.

The $\mathrm{SF}_{6}$ tracer gas wash-out-method was used to measure functional residual capacity (FRC); (for details see [19]). The $\mathrm{SF}_{6}$ equipment was available only for ten animals; therefore all FRC data presented in this study refer to ten animals.

\section{Opening procedure}

Immediately after and $3 \mathrm{~h}$ after lavage the surfactant-deficient lungs were recruited with the external PEEP set to the level which generated a peak inspiratory pressure of $50 \mathrm{cmH}_{2} \mathrm{O}$ and $\mathrm{I}: \mathrm{E}$ ratio of $1: 1$ for $5 \mathrm{~min}$.

\section{Inflection point}

The pressure/volume loop was generated using a constant inspiratory flow of $0.15 \mathrm{l} / \mathrm{s}$ and tidal volume of $1200 \mathrm{ml}$. From this loop the inflection point was determined by inspection $[20,21]$ immediately after lavage and $3 \mathrm{~h}$ after lavage (Fig. 1).

\section{Inspiratory flow pattern}

The Servo Ventilator 300 provides a pressure-regulated volumecontrolled mode (Siemens-Elema, Solna, Sweden). This mode provides the set tidal volume by regulating the inspiratory pressure to

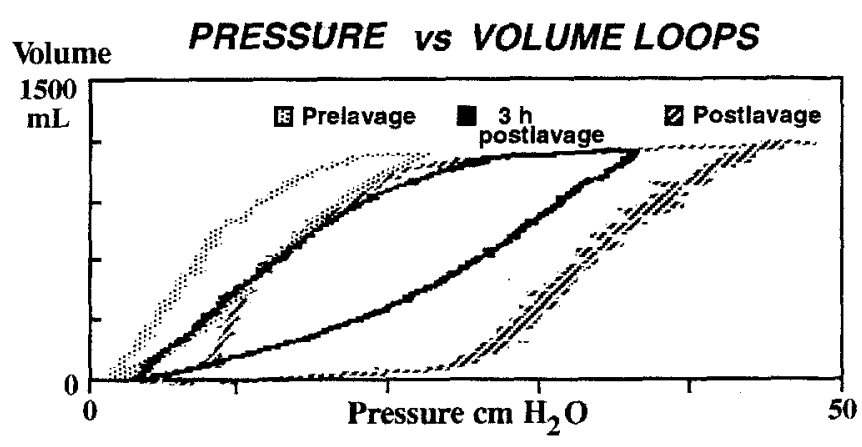

Fig. 1 Pressure-volume loops before, immediately after, and $3 \mathrm{~h}$ after lavage in one of the piglets 

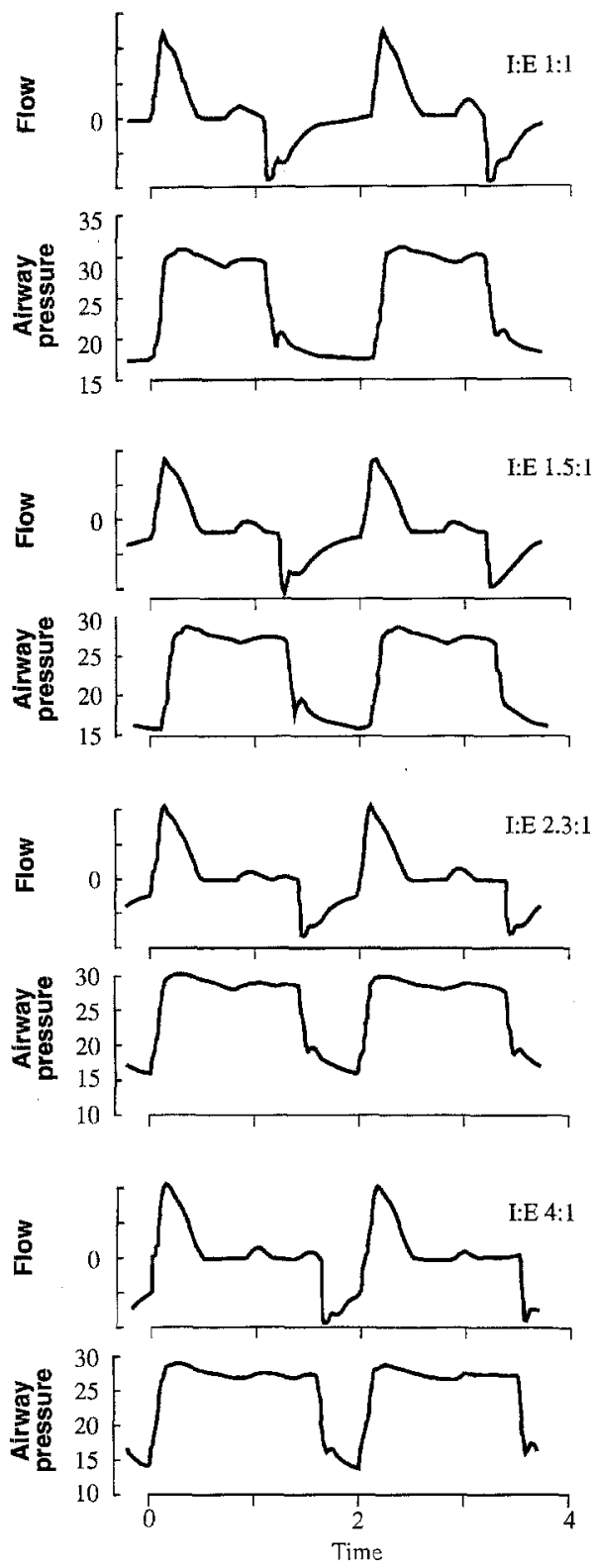

Fig. 2 Original experimental record of gas flow and airway pressure for two breaths at $30 \mathrm{bpm}$ and with (top to bottom) increasing I:E ratios. The pressure-regulated volume-controlled mode provided the set tidal volume (by regulating the inspiratory pressure to a value based on the pressure/volume conditions for the previous breath). Adjusting the drive gas pressure between each breath provided decelerating inspiratory flow and constant tidal volume for all settings. Time is given in seconds, airway pressure in $\mathrm{cmH}_{2} \mathrm{O}$, and flow in a relative scale

a value based on the pressure/volume conditions of the previous breath. Allowing the drive gas pressure to be adjusted between each breath maintains the set tidal volume within limits given by the set upper pressure limit and pressure differences between breaths not exceeding $3 \mathrm{cmH}_{2} \mathrm{O}$. Decelerating inspiratory flow was therefore delivered together with a constant tidal volume for all settings (Fig. 2).

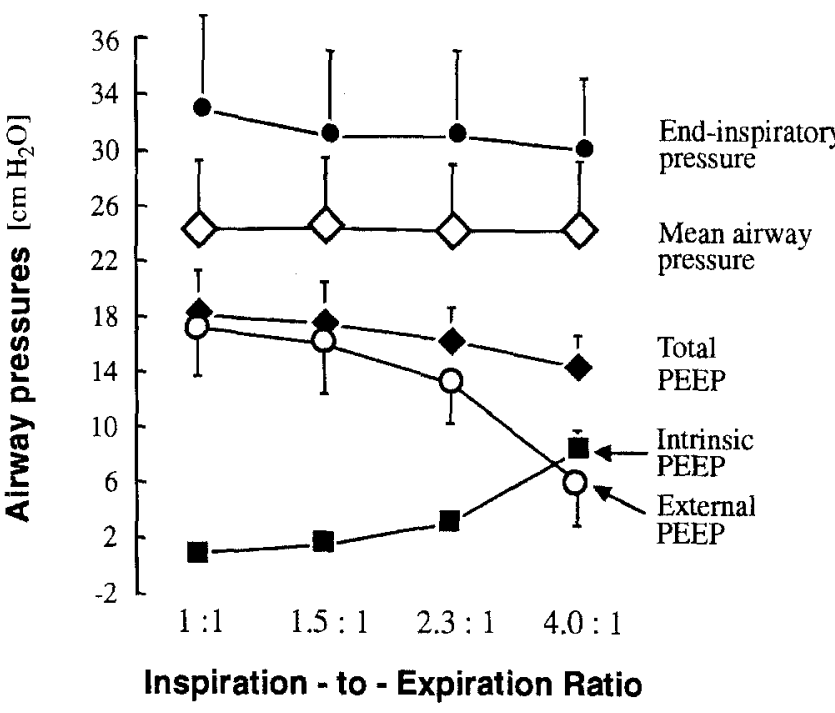

Fig. 3 End-inspiratory and mean airway pressures, the relationship between external and intrinsic PEEP, and the resulting total PEEP, with stepwise inversed $I: E$ ratio while mean airway pressure was kept constant (see Discussion: Methodological considerations). Levels of significance are given in Table 1

Experimental procedure

Following anesthesia and preparation the animals were placed in prone position. Lavage was performed with a series of 10 or 11 instillations of $37^{\circ} \mathrm{C}$ normal $0.9 \%$ saline, each of $1-1.51$ volume (for details see $[15,22])$. Postlavage a first opening procedure was performed. Thereafter the inflection point of the inspiratory limb of the pressure/volume loop was determined, followed by a second opening procedure. Ventilation was resumed $30 \mathrm{~min}$ after lavage, with the external PEEP set to $100 \%$ of the inflection point value. External PEEP was then reduced to $75 \%$ of the inflection point value [23], which maintained open lung conditions. The latter setting was then used as the reference setting with the $I: E$ ratio at 1:1. Three different I:E ratios - 1.5:1, 2.3:1, and 4:1 - were then applied randomly for $30 \mathrm{~min}$ to achieve a ventilatory and hemodynamic steady state when measurements were taken.

The reference setting included the following: decelerating inspiratory flow, ventilatory frequency $30 \mathrm{bpm}, \mathrm{I}$ : E ratio $1: 1$ and $\mathrm{FIO}_{2} 0.5$. Based on previous experimental studies in the same animal model, external PEEP was set to $75 \%$ of the inflection point (PEEP $17 \pm 4 \mathrm{cmH}_{2} \mathrm{O}$ ). Tidal volume was adjusted to $9 \pm 1 \mathrm{ml} / \mathrm{kg}$ to achieve a $\mathrm{PaCO}_{2}$ of $5.5 \pm 0.3 \mathrm{kPa}$. Prolonged inspiratory times generated increasing intrinsic PEEP, and to keep mean airway pressure constant external PEEP therefore had to be reduced.

Presentation and statistical analysis of data

Values are given as mean \pm 1 standard deviation. A standard statistics package was used (STATWIEV). Differences between the ventilatory settings were evaluated with a one-way analysis of variance for factorial measures for all paired comparisons within each variable using Scheffe's $F$ test. If significant differences were detected, a post hoc test was performed to verify the significances detected in the analysis of variance. Figure 3 presents data according to increasing $I: E$ ratio, although $I: E$ $1.5: 1,2.3: 1$, and $4: 1$ were applied at random rather than in sequence with increasing $\mathrm{I}: \mathrm{E}$ ratios. For easier reading they are connected by a spline. 
Table 1 Pulmonary function parameters

\begin{tabular}{|c|c|c|c|c|}
\hline Inspiration time $(\mathrm{s})$ & 1.00 & 1.20 & 1.40 & 1.60 \\
\hline $\mathrm{I}:$ E ratio & $1: 1$ & $1.5: 1$ & $2.3: 1$ & $4: 1$ \\
\hline Modus (A-D) & A & $\mathrm{B}$ & $\mathrm{C}$ & $\mathrm{D}$ \\
\hline End-inspiratory pressure & $32 \pm 7$ & $30 \pm 6$ & $30 \pm 6$ & $29 \pm 5$ \\
\hline Peak inspiratory pressure & $32 \pm 7$ & $30 \pm 7$ & $30 \pm 6$ & $29 \pm 6$ \\
\hline Mean airway pressure & $24 \pm 5$ & $24 \pm 5$ & $24 \pm 5$ & $24 \pm 5$ \\
\hline Total PEEP & $18 \pm 3$ & $18 \pm 3$ & $\begin{array}{l}16 \pm 2 \\
A^{*}, B^{*}\end{array}$ & $\begin{array}{l}14 \pm 2 \\
A^{*}, B^{*}, C^{*}\end{array}$ \\
\hline External PEEP & $17 \pm 4$ & $16 \pm 4$ & $\begin{array}{l}13 \pm 3 \\
\mathrm{~A}^{*}, \mathrm{~B}^{*}\end{array}$ & $\begin{array}{c}6 \pm 3 \\
A^{*}, B^{*}, C^{*}\end{array}$ \\
\hline Intrinsic PEEP & $1 \pm 1$ & $\mathrm{~A}^{*} \pm 1$ & $\begin{array}{r}3 \pm 1 \\
A^{*}, B^{*}\end{array}$ & $\begin{array}{l}8 \pm 1 \\
\mathrm{~A}^{*}, \mathrm{~B}^{*}, \mathrm{C}^{*}\end{array}$ \\
\hline Compliance & $18 \pm 4$ & $20 \pm 6$ & $20 \pm 5$ & $21 \pm 7$ \\
\hline $\begin{array}{l}\text { Functional residual capacity } \\
\text { (ml) }\end{array}$ & $1620 \pm 371$ & $1633 \pm 392$ & $1618 \pm 360$ & $1525 \pm 307$ \\
\hline $\mathrm{PaCO}_{2}$ & $5.67 \pm 0.31$ & $5.52 \pm 0.28$ & $\begin{array}{l}5.21 \pm 0.31 \\
\mathrm{~A}^{* *}, \mathrm{~B}^{*}\end{array}$ & $\begin{array}{l}5.24 \pm 0.48 \\
A^{* * *}\end{array}$ \\
\hline $\mathrm{PaO}_{2}$ & $33 \pm 5$ & $35 \pm 2$ & $36 \pm 2$ & $35 \pm 3$ \\
\hline $\begin{array}{l}\mathrm{CO}_{2} \text { production } \\
\left(\mathrm{ml} \mathrm{m}^{-2} \mathrm{~min}^{-1}\right)\end{array}$ & $268 \pm 35$ & $254 \pm 31$ & $255 \pm 25$ & $257 \pm 28$ \\
\hline
\end{tabular}

Pulmonary function parameters with stepwise inversed $\mathrm{I}$ : $\mathrm{E}$ ratio. Values are mean $\pm 1 \mathrm{SD} ; n=12$ (for FRC: $n=10$ ). A, significant difference from I:E $1: 1 ; \mathrm{B}$, from I:E $1.5: 1$; C, from I:E $2.3: 1 ;{ }^{*} p \leq 0.05$, $* * p \leq 0.01$. Airway pressures are given in $\mathrm{cmH}_{2} \mathrm{O}$ and partial pressures in $\mathrm{kPa}$.
Table 2 Hemodynamic function parameters

\begin{tabular}{|c|c|c|c|c|}
\hline Inspiration time (s) & 1.00 & 1.20 & 1.40 & 1.60 \\
\hline $\mathrm{I}$ : E ratio & $1: 1$ & $1.5: 1$ & $2.3: 1$ & $4: 1$ \\
\hline Modus (A-D) & A & $\mathrm{B}$ & $\mathrm{C}$ & $\mathrm{D}$ \\
\hline $\mathrm{SvO}_{2}[\%]$ & $62 \pm 9$ & $61 \pm 9$ & $60 \pm 8$ & $60 \pm 7$ \\
\hline $\begin{array}{l}\text { Pulmonary arterial pressure } \\
(\mathrm{mmHg})\end{array}$ & $28 \pm 4$ & $\begin{array}{l}34 \pm 8 \\
A^{*}\end{array}$ & $34 \pm 6$ & $\begin{array}{l}34 \pm 7 \\
A^{*}\end{array}$ \\
\hline $\begin{array}{l}\text { Cardiac index } \\
\left(\mathrm{ml} \mathrm{m} \mathrm{m}^{-2} \min ^{-1}\right)\end{array}$ & $5175 \pm 1059$ & $4675 \pm 1422$ & $\begin{array}{l}4475 \pm 1014 \\
A^{* *}\end{array}$ & $\begin{array}{c}4292 \pm 973 \\
A^{* *}\end{array}$ \\
\hline $\begin{array}{l}\text { Stroke index } \\
\left(\mathrm{ml} \mathrm{m}^{2}\right)\end{array}$ & $40 \pm 10$ & $34 \pm 9$ & $\begin{array}{l}33 \pm 8 \\
A^{*}\end{array}$ & $\begin{array}{l}32 \pm 6 \\
A^{*}\end{array}$ \\
\hline Shunt $(\%)$ & $10 \pm 1$ & $11 \pm 1$ & $11 \pm 1$ & $11 \pm 2$ \\
\hline $\begin{array}{l}\text { Intrathoracic blood volume } \\
\quad\left(\mathrm{ml} \mathrm{kg}^{-1}\right)\end{array}$ & $23 \pm 6$ & $21 \pm 4$ & $20 \pm 4$ & $20 \pm 4$ \\
\hline $\begin{array}{l}\text { Extravascular lung water } \\
\left(\mathrm{ml} \mathrm{kg} \mathrm{kg}^{-1}\right)\end{array}$ & $19 \pm 3$ & $\begin{array}{l}17 \pm 3 \\
A^{*}\end{array}$ & $\begin{array}{l}16 \pm 3 \\
A^{*}\end{array}$ & $\begin{array}{l}16 \pm 3 \\
A^{*}\end{array}$ \\
\hline $\begin{array}{l}\text { RV end-diastolic volume } \\
\left.(\mathrm{ml} \mathrm{m})^{2}\right)\end{array}$ & $120 \pm 23$ & $126 \pm 25$ & $115 \pm 19$ & $117 \pm 23$ \\
\hline RV ejection fraction $(\%)$ & $31 \pm 5$ & $28 \pm 5$ & $\begin{array}{l}28 \pm 6 \\
A^{*}\end{array}$ & $\begin{array}{l}27 \pm 5 \\
A^{*}\end{array}$ \\
\hline $\begin{array}{l}\text { Oxygen delivery } \\
\left(\mathrm{ml} \mathrm{m}^{-2} \min ^{-1}\right)\end{array}$ & $571 \pm 125$ & $553 \pm 146$ & $\begin{array}{l}521 \pm 109 \\
A^{*}\end{array}$ & $509 \pm 82$ \\
\hline
\end{tabular}

Hemodynamic function parameters with stepwise inversed $\mathrm{I}$ : $\mathrm{E}$ ratio. Values are mean $\pm 1 \mathrm{SD} ; n=12$. $* p \leq 0.05,{ }^{* *} p \leq 0.01$. A, significant difference from $\mathrm{I}: \mathrm{E} 1: 1 ; \mathrm{B}$, from $\mathrm{I}: \mathrm{E} 1.5: 1 ; \mathrm{C}$, from $\mathrm{I}: \mathrm{E} 2.3: 1$. 


\section{Results}

Results are presented in Tables 1 and 2 and Figs. 1-3.

Effects of lavage

Lavage reduced compliance from $26 \pm 4$ to $11 \pm 2 \mathrm{ml} /$ $\mathrm{cmH}_{2} \mathrm{O}$ and $\mathrm{FRC}$ from $674 \pm 167$ to $180 \pm 43 \mathrm{ml}$. With $\mathrm{FIO}_{2} 1.0$ and zero PEEP ventilation $\mathrm{PaO}_{2}$ was reduced from $76 \pm 4$ prelavage to $7 \pm 2 \mathrm{kPa}$ postlavage, and EVLW increased from $5 \pm 1$ to $19 \pm 3 \mathrm{ml} / \mathrm{kg}$. The inflection point was $23 \pm 2 \mathrm{cmH}_{2} \mathrm{O}$ immediately after lavage and had disappeared at the pressure/volume loop measurement $3 \mathrm{~h}$ postlavage (Fig. 1).

\section{Airway pressures}

In the reference setting $(\mathrm{I}: \mathrm{E} 1: 1)$ external PEEP was set to $17 \pm 4 \mathrm{cmH}_{2} \mathrm{O}$. Intrinsic PEEP increased with prolongation of inspiratory time. To maintain mean airway pressure constant at $24 \pm 5 \mathrm{cmH}_{2} \mathrm{O}$ external PEEP had to be reduced to 16,13 , and $6 \mathrm{cmH}_{2} \mathrm{O}$ (Fig. 3). Total PEEP was $18,18,16$, and $14 \mathrm{cmH}_{2} \mathrm{O}$. The decrease in peak and end-inspiratory pressure $\left(32 \pm 7 \mathrm{cmH}_{2} \mathrm{O}\right.$ with $\left.1: 1\right)$ paralleled the decrease in total PEEP (Fig. 3).

Ventilation, gas exchange, compliance, and lung volumes

Prolongation of inspiratory time did not affect $\mathrm{PaO}_{2}$. Compared to the $\mathrm{I}: \mathrm{E}$ ratio of $1: 1 \mathrm{PaCO}_{2}$ was lower with. I:E $2.3: 1$ and $4: 1 \quad(5.21 \pm 0.31$, and $5.24 \pm 0.48$, respectively). Compliance remained at the level of $18-21 \mathrm{ml} / \mathrm{cmH}_{2} \mathrm{O}$ in the postlavage settings. FRC (reference: $1620 \pm 371 \mathrm{ml}$ ) was reduced to $1525 \pm 307 \mathrm{ml}$ with the $\mathrm{I}$ : $\mathrm{E}$ ratio at $4: 1$. EVLW was $19 \pm 3 \mathrm{ml} / \mathrm{kg}$ with the first postlavage reference setting (I:E $1: 1)$, and it was lower in all other settings $(p \leq 0.05)$.

\section{Hemodynamics and oxygen delivery}

Cardiac and stroke indices and right ventricular ejection fraction all decreased with I:E $2.3: 1$ and $4: 1$ $(p \leq 0.05)$. With constant arterial $\mathrm{PO}_{2}$, oxygen delivery was reduced only when I: E was 2.3:1 ( $p \leq 0.05)$.

\section{Discussion}

Under open lung conditions, the present study revealed no improvement in $\mathrm{PO}_{2}$ when mean airway pressure was kept constant, but prolongation of the inspiratory time impaired hemodynamics.

\section{Methodological considerations}

In the ventilator used mean airway pressure was calculated - like in most modern ventilators - by computing the time-weighted value of the pressure measured in the ventilator circuit. To measure and calculate the time ("intrapulmonary") mean airway pressure during ventilation with intrinsic PEEP, the prevailing total PEEP should be utilized by means of intratracheal pressure measurements (not available in this study).

During the experiments there was a definite decrease in EVLW. As the I: E ratio of 1:1 was studied immediately postlavage, and was always used prior to the randomly applied settings, the largest amount of EVLW was present when $\mathrm{I}: \mathrm{E}$ was $1: 1$. Therefore, timing may evidently bias the comparison between the $\mathrm{I}: \mathrm{E}$ ratio of $1: 1$ and the other I: $\mathrm{E}$ ratios. On the other hand, the model was stable with respect to compliance, $\mathrm{PaO}_{2}$, and FRC.

In the present study the inflection point of the inspiratory limb of the pressure/volume loop was determined by inspection. The projection on the airway pressure axis of the vertex of the lower curved section was defined as the inflection point pressure. As such a procedure entails low accuracy, we have since searched for more accurate methods.

In previous studies in the same lung model [23] PEEP corresponding to $100 \%$ impaired hemodynamics (unpublished data). Therefore, during ventilation with the reference setting (I:E at 1:1) in the present study, external PEEP was set to $75 \%$ of the inflection point.

\section{Lung mechanics}

Peak and end-inspiratory airway pressure displayed identical values, which was expected with pressure-controlled ventilation and a decelerating inspiratory flow (see Fig. 1). The decrease in inspiratory pressures from 32 to $29 \mathrm{cmH}_{2} \mathrm{O}$ with increasing $\mathrm{I}$ : $\mathrm{E}$ ratio was due to the pressure-regulated volume-controlled mode and its adaptation to the increased inspiratory time. This finding contradicts results by Lessard et al. [24], and by Mercat and coworkers [25], who found no reduction in inspiratory pressures using pressure-controlled ventilation.

Compared to the reference setting, FRC was reduced by $100 \mathrm{ml}$ with an $\mathrm{I}: \mathrm{E}$ ratio of $4: 1$, which is explained by the lower total PEEP (Fig. 3). We limit this statement to the 30 -min period of investigation, as 
extended application time of reduced total PEEP might produce a change in FRC [26].

\section{Gas exchange}

$\mathrm{PaCO}_{2}$ decreased in parallel with increasing inspiratory time. This is a uniform finding in a number of studies $[6,8,26]$, but the mechanisms responsible for this improved $\mathrm{CO}_{2}$ elimination are not entirely clear [27] and could not be clarified in the present study. The virtually unchanged $\mathrm{FRC}$ in the present study does not, however, exclude recruitment of previously closed alveoli as a possible explanation.

In contrast to the present results, other investigators have found increased arterial $\mathrm{PO}_{2}$ with prolonged inspiratory times $[5,6,9,10]$. In these studies, however, FRC was neither measured nor matched. It is, therefore, conceivable that in these earlier studies prolonged inspiratory times increased $\mathrm{PaO}_{2}$ by producing intrinsic PEEP and raising total PEEP, thereby preventing end-expiratory alveolar closure and/or recruiting alveolar units. In the reference mode of the present study (I:E 1:1) PEEP was set to a level which kept the lung open during the entire respiratory cycle. As mean airway pressure was kept constant, there was no improvement in $\mathrm{PaO}_{2}$. Cole and coworkers [8], however, studying volume-controlled ventilation at matched
FRC in patients, found increased oxygen transfer when inspiratory time was prolonged with $\mathrm{I}: \mathrm{E}$ between $1.1: 1$ and 1.7:1. The increased oxygen delivery in their clinical study was, therefore, probably related more to the prolonged inspiratory time than to increased FRC.

\section{Hemodynamics}

Stroke index was lower with $\mathrm{I}: \mathrm{E}$ ratios of $2.3: 1$ and $4: 1$. Right ventricular end-diastolic volume, reflecting diastolic function of the right ventricle, was unaffected. On the other hand, right ventricular ejection fraction, reflecting systolic function of the right ventricle, was compromised with $1: \mathrm{E}$ ratios of $2.3: 1$ and $4: 1$. These observations correspond to the decreased stroke index and increased pulmonary artery pressure (increased right ventricular afterload), respectively. Other investigators have demonstrated [29] that hemodynamic performance may be influenced by longer inspiratory times even with constant mean airway pressure.

\section{Conclusion}

We conclude that under open lung conditions, in the surfactant-depleted porcine lung and increased $\mathrm{I}: \mathrm{E}$ ratio, arterial oxygenation remained unaffected while hemodynamics were impaired.

\section{References}

1. Dreyfuss D, Soler P, Basset G, Saumon G (1988) High inflation pressure pulmonary edema. Am Rev Respir Dis 137: $1159-1164$

2. Hickling K (1990) Ventilatory management of ARDS: can it affect outcome? Intensive Care Med 16:219-226

3. Kolobow T, Moretti MP, Fumagalli $R$, Mascheroni D, Prato P, Chen V, Joris $M$ (1987) Severe impairment in lung function induced by high peak airway pressure during mechanical ventilation: an experimental study. Am Rev Respir Dis 135: $312-315$

4. Parker JC, Hernandez LA, Peevy KJ (1993) Mechanisms of ventilatorinduced lung injury. Crit Care Med 21: 131-143

5. Reynolds EO (1971) Effect of alterations in mechanical ventilator settings on pulmonary gas exchange in hyaline membrane disease. Arch Dis Child 46: 152-159
6. Lachmann B, Danzmann E, Haendly B, Jonson B (1982) Ventilator settings and gas exchange in respiratory distress syndrome. In: Prakash O (ed) Applied physiology in clinical respiratory care. Nijhoff, Dordrecht, pp 141-176

7. Gattinoni L, Pesenti A, Caspani ML, Pelizzola A, Mascheroni D, Marcolin R, Iapichino $G$, Langer $M$, Agostoni $A$, Kolobow T, Melrose DG, Damia $G$ (1984) The role of static lung compliance in the management of severe ARDS unresponsive to conventional treatment. Intensive Care Med 10: 121-126

8. Cole AGH, Weller SF, Sykes MK (1984) Inverse ratio ventilation compared with PEEP in adult respiratory failure. Intensive Care Med 10: 227-232

9. Tharatt RS, Allen RP, Albertson TE (1988) Pressure controlled inverse ratio ventilation in severe adult respiratory failure. Chest 94: 755-762
10. Gurevitch MJ, Dyke JV, Young ES, Jackson K (1986) Improved oxygenation and lower peak airway pressures in severe adult respiratory distress syndrome: treatment with inverse ratio ventilation. Chest 89 : 211-213

11. Lain DC, Di Benedetto R, Morris SL, Van Nguyen A, Saulters R, Causey D (1989) Pressure control inverse ratio ventilation as a method to reduce peak inspiratory pressure and provide adequate ventilation and oxygenation. Chest 95: 1081-1088

12. Abraham E, Yoshihara G (1989) Cardiorespiratory effects of pressure controlled inverse ratio ventilation in severe respiratory failure. Chest 96: 1356-1359

13. Marini JJ, Kelsen SG (1992) Re-targeting ventilatory objectives in adult respiratory distress syndrome: new prospects - persistent questions (editorial). Am Rev Respir Dis 146: 2-3 
14. Nielsen JB, Sjöstrand UH, Edgren EL, Lichtwarck-Aschoff M, Svensson BA (1991) An experimental study of different ventilatory modes in piglets in severe respiratory distress induced by surfactant depletion. Intensive Care Med 17: 225-233

15. Lichtwarck-Aschoff M, Nielsen JB, Sjöstrand UH, Edgren EL (1992) An experimental randomized study of five ventilatory modes in a piglet model of severe respiratory distress. Intensive Care Med 18: 339-347

16. Lichtwarck-Aschoff $M$, Zeravik $J$, Pfeiffer UJ (1992) Intrathoracic blood volume accurately reflects circulatory volume status in critically ill patients with mechanical ventilation. Intensive Care Med 18: 142-147

17. Lichtwarck-Aschoff M, Leucht S, Kisch HW, Zimmermann G, Blümel G, Pfeiffer UJ (1994) Monitoring of right ventricular function using a conventional slow response thermistor catheter. Intensive Care Med 20: 348-353

18. Lewis FR, Elings VB (1978) Microprocessor determination of lung water using thermal-green dye double indiactor dilution. Surg Forum 29: 182-184

19. Larsson A, Linnarsson D, Jonmarker C, Jonson B, Larsson H, Werner O (1987) Measurement of lung volume by sulfur hexafluoride washout during spontaneous and controlled ventilation: further development of a method. Anesthesiology 67 : $543-550$
20. Lemaire F, Harf A, Simmoneau G, Matamis D, Rivara D, Atlan G (1981) Echanges gazeuz, courbe statique pression-volume et ventilation en pression positive de fin d'expiration. Etude dans seize cas d'insuffisance respiratoire aigüe de l'adulte. Ann Fr Anesth Reanim 5: 435-441

21. Holzapfel L, Robert D, Perrin F, Blanc PL, Palmier B, Guerin C (1983) Static pressure-volume curves and effect of positive end-expiratory pressure on gas exchange in adult respiratory distress syndrome. Crit Care Med 11(8): 591-597

22. Lachmann B, Robertson B, Vogel J (1980) In vivo lung lavage as an experimental model of respiratory distress syndrome. Acta Anaesthesiol Scand 24: 231-236

23. Sjöstrand UH, Lichtwarck-Aschoff $M$, Nielsen JB, Markström A, Larsson A, Svensson BA, Wegenius GA, Nordgren KA (1995) Different ventilatory approaches to keep the lung open. Intensive Care Med 21: $310-318$

24. Lessard MR, Guérot $E$, Lorino $H$, Lemaire F (1994) Effects of pressurecontrolled ventilation with different $\mathrm{I}$ : E ratios versus volume-controlled ventilation on respiratory mechanics, gas exchange, and hemodynamics in patients with adult respiratory distress syndrome. Anesthesiology 80: 983-991
25. Mercat A, Graïni L, Teboul JL, Lenique F, Richard C (1993) Cardiorespiratory effects of pressure-controlled ventilation with and without inverse ratio ventilation in the adult respiratory distress syndrome. Chest 104: 871-875

26. Sydow M, Buchardi H, Ephraim E, Zielmann S, Crozier TA (1994) Longterm effects of two different ventilatory modes on oxygenation in acute lung injury. Comparison of airway pressure release ventilation and volume-controlled inverse ratio ventilation. Am J Respir Crit Care Med 149: 1550-1556

27. Sykes MK, Lumley J (1969) The effect of varying inspiratory: expiratory ratios on gas exchange during anesthesia for open-heart surgery. Br J Anaesth 41: 374-380

28. Perez-Chada RD, Gardaz J-P, Madgwick RG, Sykes MK (1983) Cardiorespiratory effects of an inspiratory hold and continuous positive pressure ventilation in goats. Intensive Care Med 9: 263-269

29. Berman LS, Downs JB, Van Eeden A, Delhagen D (1981) Inspiration:expiration ratio. Is mean airway pressure the difference? Crit Care Med 9: 775-777 